\title{
Reforms growing on the farm
}

\section{Washington}

US agricultural research, long criticized for its lack of peer review and reliance on political handouts, will get an overhaul and expansion following Congressional approval of a five-year, $\$ 1,000$ million research programme. The US Department of Agriculture (USDA) intends to increase the fraction of competitive, peerreviewed grants, similar to those awarded by the National Institutes of Health (NIH) and the National Science Foundation, from less than 5 per cent of the agency's total research, to over 30 per cent.

Known as the National Research Initiative, the programme also marks the beginning of a ten-year, $\$ 500$ million project to map the genomes of key food plants, an effort that will run in parallel with NIH's Human Genome Project.

Although the programme got strong verbal support from Congress, it emerged from last month's budget negotiations with only three-quarters - $\$ 73$ million of its expected first-year funding, and a surprisingly restrictive 14 per cent cap on "indirect costs" at the universities that receive grants was imposed.

Of the two, the cap on overheads may be the more serious problem. Inserted into the 1991 appropriations bill by congressional defenders of the traditional agricultural schools, the provision says that universities may only take 14 per cent off the top of a USDA grant to pay for overhead costs such as heating, building upkeep, and support staff. That figure is in line with the lowest figures from agricultural schools, which tend to have lower costs, but is far below the $60-80$ per cent figure common to many large research universities and institutions.

Rosemary Grady, programme director for the initiative, notes that last year congress mandated a 25 per cent cap on USDA research grants and "that didn't seem to hurt the quality or the quantity of our applications." Although many universities had to take a loss on portions of a USDA grant, only one actually turned an award down last year, she says.

But a 14 per cent cap may be another matter entirely. Grady says "there is no way to predict what the impact of that will be", given that universities have already shown that they are willing to accept a low indirect-cost ceiling in order to get some USDA grants. But Jane Corlette, director of government relations at Harvard University, says "there's obviously a limit at which that become impossible". Harvard's normal indirect cost rate is about 60 per cent. "In specific cases, if the dean is willing to take the loss, we may accept the [ 14 per cent ] rate, but not happily. It's clearly not fair. USDA is not paying what the research costs." As a result, she says, "we can't afford to take a lot of USDA money." Despite such misgivings, the programme represents a $\$ 30$ million increase in USDA's competitive research programme.

Funding, according to the USDA programme plan, is to rise by $\$ 50$ million a year to $\$ 300$ million in 1995 .

The initiative, according to John Jordan, administrator of USDA's cooperative state research service, will be divided into four general areas of priority: 40 per cent of funding will go to individual investigator-initiated grants, modelled loosely after NIH awards; 30 per cent will go to multi-disciplinary team grants, such as those between economists and agronomists; 20 per cent will go to "mission-linked" grants, such as the plant genome programme; and 10 per cent will go to strengthening institutions and individual laboratories that have not traditionally been strong agricultural research centres.

Although the plant genome effort is scheduled to run at about $\$ 50$ million per year, Congress appropriated only about $\$ 22$ million for genome studies in 1991. With internal funding shifts, "and a good tail wind", the programme may finish the year at about $\$ 25$ million, a level that will allow the programme to start and ramp up to full funding next year, Jordan says.

Christopher Anderson

\section{Melbourne}

Most scientists, according to a survey conducted by the Royal Melbourne Institute of Technology (RMIT), are unhappy with the way daily newspapers cover science stories - but it reports, they feel happier when they are in the story. Of 85 scientists questioned by the RMIT, threequarters criticized news reporting for too much emphasis on "breakthroughs" and the uniqueness of results, and 70 per cent thought that information crucial to the understanding of the work was omitted.

But when asked to evaluate stories that involved them directly, these general allegations seemed no longer to apply. Only 2 per cent complained of being misquoted; 74 per cent found no inaccuracies, 88 per cent believed that no relevant information had been left out, and 68 per cent rated the results of their interviews "highly satisfactory". All the scientists interviewed agreed that popular news coverage of science issues was important for the public, but only 84 per cent thought it was important for the scientist.

According to John Wallace, journalism co-ordinator at RMIT, these results suggest that the science reporting is more professional than scientists in general believed, although "scientists may be a little less critical of the news process when they themselves are getting publicity."

Tania Ewing

\section{UK RESEARCH COUNCILS}

\section{Belt-tightening at MRC}

\section{London}

EsTIMATED overspending by $£ 3.5$ million during the current year has forced the Medical Research Council (MRC) to freeze new staff appointments and to postpone the purchase of expensive items of equipment until the next financial year begins in April 1991. Eighty-three researchers who won grants in July have also been asked to delay the start of their projects.

The new measures are the latest in a series of cutbacks forced upon the MRC by financial pressures, and follow decisions to close several MRC research groups in order to release funds for new research in the coming years (see Nature, 346, 685; 23 August 1990 \& 348, 6; 1 November 1990). Nick Winterton, head of the MRC secretariat, says the measures are necessary because both inflation and pay increases have exceeded the MRC's forecasts.

Although the research councils may carry over a small surplus or deficit from year to year, Winterton says it would be "bad financial management" not to balance the books this year, given the gloomy economic forecasts for 1991-92.

Sir Aaron Klug, director of the Laboratory of Molecular Biology in Cambridge, one of the MRC's largest research units, says that individual scientists planning new research may be "badly affected" by the funding squeeze, although the majority of current work should not suffer. Klug says the Treasury is partly to blame for the financial problems now facing MRC because of its refusal to recognize a "sophistication factor", which means that the price of equipment and reagents has risen faster than the general rate of inflation.

MRC secretary Dai Rees wrote to all MRC research unit directors on 2 November, to explain the staff and equipment freezes, which he described as "exceptional measures". The MRC was last forced to take similar action during the economic recession of $1980-81$. At least $£ 1$ million of the projected $£ 3.5$ million deficit is due to overspending in $\mathrm{MRC}$ research units.

Winterton says that units are given a budget at the start of each financial year, and must spend within it. If units overspend, he says, "in a sense, that's their problem".

Peter Aldhous 